\title{
XXVIII. On the Phœnomena of Platinum and other Wires in inflammable Media
}

\section{J. Murray}

To cite this article: J. Murray (1817) XXVIII. On the Phœnomena of Platinum and other Wires in inflammable Media, Philosophical Magazine Series 1, 49:226, 120-122, DOI: $10.1080 / 14786441708637855$

To link to this article: http://dx.doi.org/10.1080/14786441708637855

册 Published online: 27 Jul 2009.

Submit your article to this journal $₫$

Џ Article views: 2

Q View related articles $₫$ 
line lens; on the contrary, I think that a convex glass of a less magnifying power than that usually required after the renoval of cataract, may be frequently employed to great advantage in cases of conical cornea.

Were any further arguments than those arlduced necessary to prove that the short sight of the pratient is occasioned by the morbid thickness of the cornea, and not by the superabundant quantity of the aqueous humour, as has been supposed, it would be, the well-known fact, that water possesses little comparative refractive power; while, from the dense structure and the form of the conical cornea, it is as evident that its powers of refraction must be very considerably increased. Indeed, gutta serena would certainly be produced by the backward pressure of a superabundant quantity of aquenus humour against the vitreous humour and retina, long before it would occasion a protrusion of so dense and firm a tunic as the transparent cornea; and 1 have actually seen gutta serena result from this cause, without any material convexity of the cornea being perceptible, although from overdistention it felt to the touch nearly as hard as an egg-shell.

Although I may have failed in convincing my readers of the accuracy of some of the opinions which I have ventured to submit in this paper, yet 1 have the gratification of knowing that $I$ have fully proved the important fact, of having successfully carried into effect a mode of treatment capable of restoring vision in a case incurable by other surgical meaus, and which, as far as I have been able to ascertain, has hitherto never been employed by any other person.

XXVIII. On the Phcenomena of Platinum and other Wires in inflammable Media.

\section{To Mr. Tilloch.}

Sir, - A Amiring, as I did, the important and beautiful communication of Sir Il. Davy on the Phrenomena of Platinum Wire and that of Palladium in some inflammable Media, it may not be uninteresting for you to receive an account of my experiments. "Experimentam fiut" is the impression which will ever govern my philosophical studies: and seeing that the noblest erection of theory which the human mind can rear, must yield the precedency to a single fact established by the hand of experiment, I shall in the present imposing march of chemical discovery be fearful of trusting to the illusions of fancy, and regard with a jealous eye the portraiture drawn by the pencil of hypothetical dogma. 
1. Phatinum wire continues red hot in explosive mixtures of inflammable gases. Also in the vapour of naftha, alcohol and ether. I found it in like manner effective in mitric, \&c. cihcrs, as well as the sulphuric; in phosphorized ether and alcoholic solution of cumphor; oil of wine, vapour of sulphurel of carlon, and of camphor.

2. I discovered that gold, silver, steel, and copper wires were phosphorescent, though they did not continue red hot in the vapour of ethers, oil of wine, and sulphweret of carbon.

3. Platinum uire and that of gold, silver, sleel, and copper, when phosphorescent in the vapour of ethers and oil of wine, evolve a peculiar acrid acid gas, rendered sensible by the contiguity of a stopper moistened with ammonia. This acid gas acts violently on the eyes, exciting tears.

4. A glass rod and piece of the stem of a tobacco-pipe will, in the vapour of ethers and oil of wine, be phosphorescent; and in like manner contribute by this minimum combustion to the formation of the acid gas in question. I need scarcely ard that, prior to the introduction of the wires, \&c. into the volatile inflammable medium, such should be made red hot.

The phospluorescent flame is very livelily exhibited in introducing copper wire, \&c. into phosphorized ether; and the platinum wire continues to glow very vividly over oil of wine, until the ethereal matter is all expended in the production of the acid gas, leaving a residuum, which seems to be a peculiar fixed oil, combining with potassa and soda, and highly inflammable. Spcc. gr. less than that of water.

5. When gold wire entwines a coil of platinum wire, and the wires are heated and plunged into the ethereal medium, the platinum continues to glow red hot, and the gold wire will be seen dark among the threads of platinum.

6 . The phosphorescent flame exhibited under the preceding circumstances I did not find susceptible of igniting either olefiant or coal gas, or phosphorized ether, sulphur, or sulphuret of carbon. A jet of coal gas urged on platinum wire red hot, in oil of wine, $8 \mathrm{c}$. caused it to glow more vividly. If the platinum wire be depressed lower than the focus, where the ignition is most intense, the phosphorescent flame will be displayed, and the platinum will cease to be red hot.-The display of phosphorescence may be repeated frequently, particularly with glass and alumina ; for at each successive immersion it will be renewed. Two coils of platinum and steel wires in contact, both previously made red hot and plunged simultaneously into the vapour of ether, exhibit an interesting appearance. In the first instance the steel wire will 
continue red hot, while the platinum is not luminous. On the moment, however, the reverse takes place, and the platinum becomes luminous, while the iron wire instantly ceases to be so; nor does the latter exhibit phosphorescence when the platinum glows.

I am very respectfully, sir,

Your ohedient humble servant,

Surry Institution, Feb. 3, 1817.

J. Murray.

P. S.-I plunged the red hot platinum wire into the vapour of the following essential oils, but did not succeed in maintaining it in this state-Origanum, nulmeg, lavender and cloves. In the vapour of sulphur I had a lambent phosphorescent flame.

XXIX. Geological Queries, regarding the Coal Strata, Basalles, and Red Marl, of Northumberland and Durham, and on the Appearances of Cual, ङैc. in Lincolnshire. By A CorreSFONDENT.

\section{To Mr. Tilloch.}

SIR, $-T_{\text {HE extreme kindness and urbanity of your very able }}$ correspondent Nathaniel John Winch, Esq. in replying, so promptly, in p. 100 of vol. xlvii, to the 5 queries which 1 had taken the liberty of proposing to him, in p. 12 of that volume, ought long ago to have received my grateful acknowledgements: but gathering from his replies, that the Geological Society were in possession of important communications from him, on the subjects of my inquiries, I have abstained from troubling him further; until now, when having read the Ist part of Vol. iv. of their Transactions, 1 am happy in being able, sincerely to thank and congratulate Mr. W. on having produced (near 3 years ago) beyond comparison the best Paper, for its copious and practically useful details, which that Society have yet laid before the public : accompanied at the sane time by my regret, that the Society have not thought fit to include also in this part, another Paper, which 1 learn that Mr. W. has (more than 9 months ago) presented to them, regarding the east part of Yorkshire.

Mr. W.'s goodness, and zeal for the advancement of "practically useful Geology, will I trust excuse the liberty I am taking, in again reviving, and considerably amplifying, some of the subjects of my Five Queries, in the page above referred to, viz.

1st. Are not some of the lower individual seams of Coal, and their floor and roof Measures, of Limestone, \&c, which are worked in the detached part of Durham and NE part of Northumberland, traceable, although perhaps varying much in thickness and quality, round the east and south flanks of the Cheviot 